\title{
COMMENT
}

\section{The uncertain fate of the National Institutes of Health (NIH) pediatric research portfolio: In support of an investment strategy to improve the public health of the nation through perinatal research}

\author{
David K. Stevenson ${ }^{1}$, Gary M. Shaw ${ }^{1}$ and Michael Katz ${ }^{1,2}$ \\ Pediatric Research (2018) 84:321-322; https://doi.org/10.1038/s41390-018-0036-6
}

Gitterman, et $\mathrm{al}^{1}{ }^{1}$ provide a sobering review of the legislative history underlying the record of federal pediatric research spending over an approximately two decade period, as well as the Pediatric Research Initiative (PRI) and perinatal funding relative to total pediatric research funding. Indeed, the authors' perspective on the future of federal support for biomedical and pediatric research is not reassuring. Moreover, a most telling point made in their article is that the actual purchasing power of the pediatric research portfolio has been reduced over the years by almost $16 \%$, and that this financial deprivation has had a real impact on the ability of pediatric investigators to conduct research. Another serious side-effect of this substantive contraction of federal support is the more serious threat to the training of new pediatric researchers and for those who are trained, their more likely discouragement from continuing in an academic investigative career. One need only to be tangentially affiliated with training our pediatric-minded residents, fellows, and $\mathrm{PhD}$ post-docs to sense their trepidation to pursue research careers in the field as they watch their faculty mentors try harder and harder to advance the knowledge base with ever-lower NIH paylines.

Notably, the-well intentioned Children's Health Act (CHA) in 2000, which was designed to address the projected under investment in pediatric research, introducing the PRI and the National Children's Study (NCS), has been a catastrophic disappointment. For all intents and purposes, the NCS seemed like a good idea-to explore the links between environmental exposure, development, and health outcomes in children and ultimately adults. However, over a fourteen-year period, there were increasing concerns about its scientific methods, oversight and management structures, as well as increasing costs. Thus, its likelihood of success dimmed, and it became obvious to a special review group that new biological insights into the factors that impact child health and new enabling technologies had outpaced the byzantine and faltering effort of the NCS, because of 'too many cooks in the kitchen' and an unsettled menu for scientists and ultimately nothing to serve the public, which had been waiting for over a decade already. In 2014, the NCS was unceremoniously discontinued, while the PRI remained a nominal part of the budget-but mainly just an accounting mechanism for only a carefully defined portion of all pediatric research spending which would not take into consideration any new investigatorinitiated pediatric research projects. The other problem with PRI was that its purpose to expand various aspects of the pediatric research portfolio did not include new funds for any such efforts, making the task of the NICHD especially vexing as the Institute tried to expand its pediatric research portfolio without changing its spending levels.

With the demise of the NCS, the Environmental Influences on Child Health Outcomes (ECHO project) arose from the administrative ashes, with a narrower focus on pediatric outcomes and environmental influences relying on existing data sources rather than a comprehensive longitudinal study approach original to the NCS. Any real hope of a concerted and substantial investment in pediatric research that would likely impact public health on a population scale lost its foundation. This circumstance amounted to a loss of focus on the beginning of the life course, perhaps the most important point to acknowledge, stemming from the Gitterman article. In fact, the recognition is further refined toward the end of the piece which introduces the concept of perinatal research. We concur that the perinatal period is critical to the future of pediatric research and precision health care in general. Nonetheless, shown in the same figure with the accounting for PRI funding is the funding for perinatal research, which, although slightly higher, tracks with the former and has remained relatively constant over the years despite the various legislative acts and changes in policy.

We agree with the first conclusion and recommendation of our colleagues about the need for specific appropriations dedicated to the PRI. However, we would especially emphasize the second conclusion and recommendation that there should be an increase in the proportion of pediatric research support directed towards investigations conducted by obstetricians and maternal-fetal medicine specialists-and would add that such investigations should be undertaken in conjunction with their pediatric and neonatology colleagues, turning this nation's attention to the health of the mother and that of her fetus and newborn. There is little doubt in the proposition that prenatal influences contribute to postnatal conditions - the research to identify, ameliorate, or prevent such influences is woefully underfunded. Such a shift in our funding priorities would be most likely to ensure a long-term

\footnotetext{
${ }^{1}$ March of Dimes Prematurity Research Center at Stanford, Division of Neonatal and Developmental Medicine, Department of Pediatrics, Stanford University School of Medicine, Stanford, CA, USA and ${ }^{2}$ Departments of Pediatrics and Public Health, Columbia University, New York, NY, USA

Correspondence: David K. Stevenson (dstevenson@stanford.edu)
}

Received: 10 April 2018 Accepted: 11 April 2018

Published online: 6 July 2018 
return on investment measured in the health of infants, children, and adolescents-but ultimately in the health of adults and the nation as a whole. The fact that a large portion of such a return on investment would likely occur later in the life course, delaying political gratification, should not deter such wise action.

We would like to make several other specific points related to this argument. Fundamental discovery (basic science), translational and applied science, the latter in the form of clinical trials, represent the pipeline for precision public health-to predict, prevent, and cure precisely. In order to address the grand health challenges of humanity, 'convergence' or 'transdisciplinary' science is needed. We have recently discussed the challenges associated with supporting such efforts through current academic structures and research funding mechanisms. ${ }^{2}$ Teams of scientists and hybrid networks within and across institutions are needed for breakthrough discoveries and rapid deployment of new remedies that are accessible to the public in ways that avoid disparities in health outcomes. Moreover, the biologic and social determinants of health should be on an equal footing with respect to research. And we believe strongly that the training of new perinatal and pediatric investigators along with competitive funding to sustain their productivity over the ensuing years is critical to this undertaking.

Finally, pregnancy-related research should be recognized as fundamental to the life course approach to precision health. Moreover, more investment in basic research focused on the phenomenon of tolerance (or loss of tolerance) during pregnancy might provide insight into to what nature can teach us about striking the right balance between an oxidative and anti-oxidative disposition on a planet rich in iron, oxygen, and light. Such investment would only complement ongoing research on human development, cancer, autoimmunity, and aging, as well as infectious disease. Our current approach to health careattempting to retrieve people from various pathologic states later in life-might be avoided altogether by investing in research on pregnant women and their fetuses, establishing from the outset, healthier life course trajectories. Thus, there is so much more at stake than just improving the upward slope of pediatric research funding, in particular perinatal research and PRI-related research. It will take more than simple policies that require people across the life span to be included in clinical research studies. It will take a major cultural shift, reflected in a redirection of federal research funds to obstetric and pediatric investigative efforts, in order to actualize the promise of precision health-better prediction, prevention, and precise therapies.

\section{FUNDING}

This work is supported by funding from the March of Dimes Prematurity Research Center at Stanford (MOD PR625253), The Bill and Melinda Gates Foundation (Award \# OPP1154964), and the Hess Research Fund.

\section{AUTHOR CONTRIBUTIONS}

D.K.S., G.M.S., and M.K. each contributed to the drafting and revising of the article and final approval of the published version.

\section{ADDITIONAL INFORMATION}

Competing interests: The authors declare no competing interests.

Publisher's note: Springer Nature remains neutral with regard to jurisdictional claims in published maps and institutional affiliations.

\section{REFERENCES}

1. Gitterman D. P., Langford W. S., Hay W. W., Jr. The uncertain fate of the National Institutes of Health (NIH) Pediatric Research Portfolio. Pediatr. Res. (2018). https://doi.org/10.1038/s41390-018-0035-7. (Epub ahead of print).

2. Wise, P. H., Shaw, G. M. \& Druzin, M. L. et al. Risky business: meeting the structural needs of transdisciplinary science. J. Pediatr. 191, 255-258 (2017). 